\title{
Impact of Investors' Loss Aversion and Overconfidence on Market Performance Evidence from China Stock Markets
}

\begin{abstract}
Hu Yiwen
Rocky Hill Country Day School, 530 Ives Road, East Greenwich, Rhode Island, 02818, USA

*Corresponding author. Email:cynthiahuyw@gmail.com

ABSTRACT

This paper proposes a research that aims to answer how the loss-aversion and overconfidence treated as potential investor biases can potentially affect the performance of the listed companies operating in the market. This paper examines how loss aversion of investors influences the companies' performance and how overconfidence of investors impacts on the companies' performance. The research proposes a potential econometric model to represent the impact of investors' loss aversion and overconfidence on market performance and does a solid analysis on the behavioral economics especially in China stock market. Many studies have been done on the relationship of biases and investment decision making but still there is a gap to bring in new moderators and mediators in it. With the empirical model built in this research, more information about behavioral economics could be revealed.
\end{abstract}

Keywords: Loss-aversion, overconfidence, stock market, behavioral finance

\section{INTRODUCTION}

In modern financial theory, the efficient markets hypothesis defines the integration of asset prices and available information and reveals that the market efficiency is dependent on the perfect rationality of investors. However, research has found that the financial market is operated differently compared to what the market efficiency theory suggests. This is explained by the financial market anomalies, and these anomalies are significant phenomena that lead to the emergence of behavioral finance.

The behavioral finance theory is built with some assumptions, the first is that the investors are not necessarily be perfectly rational in making investment decisions, while the second assumption is the ineffective arbitrage carried by perfectly rational investors. It is been noted that the investors' behavior can be significant impacted and thus influence the investment choices and decisions making[8]. Suggested by the classical financial theories, the investors are always being rational, however, in real market operations, investors are likely to conduct so call the mental calculation that can potentially affect their behavior and lead to the mistreatment of available information. Intuitively, the mentioned investor biases that affect the investment decision making, can also have significant impact on company performance as one logical consequence.

Given the current consideration, this paper proposes a research that aims to answer how the loss-aversion and overconfidence treated as potential investor biases can potentially affect the performance of the listed companies operating in the market. The sentiment variables are being proofed to have significant power to explain the investor behavior, but there are relatively limited research has documented their impacts on company performance. This research will classify the sentiment into two dimensions: the one is loss aversion while the other is overconfidence. This paper is structured as the following. Chapter two is the section of literature review. Chapter three is the section of methodology with research limitation, while chapter four is the conclusion part.

\section{LITERATURE REVIEW}

In theory, the efficient market hypothesis is majorly based on the idea that the investors' investment rationality is perfect without bias. However, numerous studies have disproved the condition of the hypothesis with the explanation of financial market anomalies. De Bondt \& Thaler (1985) firstly challenged the efficiency 
of efficient market hypothesis and the importance of emergence of behavioral theory. They showed that the financial market is not effective [8]. Furthermore, it would be interesting to assess whether loss aversion and overconfidence are significant in contributing to challenge the efficient market hypothesis $[1,9]$.

\subsection{Loss Aversion Bias}

The concept of loss aversion is firstly explored through the prospect theory [12]. In particular, the prospect theory suggests that the investors would have different valuation on gain and loss and therefore the investors tend to make decisions based on gain rather than loss under this bias. It is also suggested that the investors that subjected to loss aversion if they have realized gain rather than realized loss and want to rapidly sell the shares to prevent price volatility. This bias is important since it influences the buy and sell decisions of the investors. Furthermore, Shiller (1998) documented that the human tendency to feel pain from losing caused by error would lead to more intention to avoid the pain, and thus losses [16]. Aftalion (2002) provided some specific examples of the regret and loss aversion, and asserted that the investor who is not subject to loss aversion should be less happy [1].

Investors tend to be more sensitive to loss than to gain. In case if the investor is very sensitive to loss, he or she will always seek to avoid the loss that could potentially influence his decision making process in an absolute way. In fact, the gaining shares are sold much more than the losing shares, which reveals that the fear sentiment of investors that prevent them to realize losses. Chau et al (2011) and Rephael et al. (2012) used prospect theory to study and explain the decision making process of investors [5, 14]. They have proposed a normative model that allow the investors to maximize their utility function. Benartzi \& Thaler (1995) interpret the gap between stock returns and bond returns [3]. The researchers mentioned above use the approach to determine the frequency of portfolio valuation and let the investors to be indifferent by assuming they are loss averse. Therefore, when the evaluation interval is narrowed, the loss aversion sentiment would cause the stocks being less attractive to the investors. Barberis et al. (2001) find that the fluctuations of the value of investors' wealth causes loss aversion sentiment and the degree of loss aversion is dependent on investors' previous investment performance [2]. Thaler \& Johnson (1990) find similar results and concluded that the loss aversion is dependent on investors' historical investment results and triggers sentiment on gain and loss [17]. In other words, in case if the investor obtained realized historical gains, he would be weakly averse to loss, but if he lose in his investment history, he would become more and strongly loss aversion investor. In general, the loss aversion sentiment would lead and mentally force the investors not to sell the shares if the share price went down and they were experiencing loss. This is due to the reason that those investors would tend to expect that the loss can be recovered through time and the fear of things may get lost once again.

\subsection{Overconfidence}

Overconfidence is one other psychological bias that effectively reflects the optimism. Normally, the overconfidence sentiment appears from overestimation of different situations, and overconfidence exists when the investor is relatively or very confident of his or her knowledge over the investment and the abilities to obtain abnormal returns. Overconfident investors could overestimate the their capability in generating information and data and their ability to make forecast. In practice, the overconfident investors would normally give privilege to the information they obtained compared to the public available information. Russo \& Schoemaker (1992) empirically studied the confidence of investors and find that only $1 \%$ of the investors correctly make nine out of ten judgment on simulated scenarios while $90 \%$ of the investors only make 4-7 correct judgments on the simulated scenarios [15]. They in further conclude that the most individuals would have much more confidence over their general knowledge. Dreman et al. (2001) studied the overconfidence based on 220000 US families and find that the male investors would tend to have more overconfidence than female due to the differences of manner of thinking and investment preferences inherent differently in male and female behavior [9]. Daniel et al. (1998) find that the investors are more likely to value higher about their own information and knowledge than the other general available information through the application of crosssectional model [7]. Benos (1998) find that even the risk neutral investors are more likely to overestimate the precision of their private information [4]. Jung et al (2009) also find that investors are likely to disagree with each other and hold different investment portfolios, leading to mean variance inefficient market portfolio [11]. The researchers mentioned above show how the overconfidence lead to price volatility.

Overconfidence sentiment can effectively cause the investors to blindly belief their knowledge about the market and its fluctuation, and are able to generate abnormal returns by outperform the market through the anticipation of market fluctuation. Daniel et al. (1998) argue that there are two kinds of investors existed in the market, in which the first one tend to dispose their private information and thus subjected to overconfidence, while the second one tend to dispose the public information and subjected to rational investors [7]. They shows that the overconfidence leads to overestimation of the accuracy of information. Interestingly, overconfidence can also lead to 
overreaction. De Bondt \& Thaler (1985) empirically tested that the losing portfolio will have $25 \%$ greater performance in the future than the gaining portfolio [8].

Intuitively, overconfidence can dominate the investors' rationality and have long-term impacts. It is also logical to say that the investors who are overconfidence would more likely to anticipate greater profit than the rational investors due to risk taking. Kyle \& Wang (1997) have confirmed that the overconfidence can significantly dominate rationality, and find that the overconfidence investors are more likely to generate higher expected returns [13]. Hirshleifer \& Leo (2001) also find that the overconfidence investors did better performance than the rational investors in exploiting asset misplacing caused by market noise [10]. Chuang \& Susmel (2011) in further find that the individual investors are more overconfidence than the institutional investors. They find that the individual investors in Taiwan trade more aggressively than the institutional investors when the market is following gains [6]. There are limited research has conduct the empirical analysis on how the sentiments, such as overconfidence and loss aversion can impact on companies' performance through transition effect.

\section{METHODOLOGY}

This section will provide detailed information on research methodology, including the description of data and data collection, the type of the research, the analytical econometric model proposed to analyze the data and research limitations. This research is a secondary research that only use quantitative data to analyze and explain the subject matter, and therefore this research is a quantitative research.

\subsection{Potential Data}

The sample is designed to have consist 100 nonfinancial public listed companies in China's A share market from year 2000 to year 2020. Quarterly data will be collected from Wind platform. The variables include the dependent variable return on equity as the measure of companies' performance, and the independent variables include the market size of the company, the market capitalization, net earnings, loss aversion and overconfidence. The loss aversion is measured by percentage variation of transaction volume, while the overconfidence is measured by percentage change of shares held by shareholders.

\subsection{Empirical Models}

In order to properly analyze the data, ordinary least square (OLS) is used to perform panel data analysis. The use of OLS is appropriate since the loss function of the model aims to find the best fitted values with smallest squared errors. Based on the data collected, the variables of interest are loss aversion and overconfidence, while other independent variables are controlling variables. The OLS regression model is given by:

$$
\begin{array}{r}
R O A_{i}=\beta_{0}+\beta_{1} L A_{i, t}+\beta_{2} O C_{i, t}+\beta_{3} \text { size }_{i, t} \\
+\beta_{4} \text { mcap }_{i, t}+\beta_{5} N E_{i, t}+\epsilon_{i, t}
\end{array}
$$

where ROA is the return on assets measured by the net income to total assets of the company, SIZE is the market size of the company obtained from Wind platform. OC is the overconfidence measured by the percentage change of shares held by shareholders, LA is the loss aversion measured by the percentage variation of transaction volume. MCAP is the market capitalization measured by the total market value of the company's outstanding shares and NE is the net earnings of the company measured by the difference of company's revenues and costs. The $\beta$ is a vector of unknown parameters to be estimated that interprets the potential impact of the corresponding variable. The $\epsilon$ is the error term, while the use of OLS is to minimize the squared estimates of the error term.

The use of panel data with the incorporation of cross sectional approach requires the model to be consistent and unbiased in order to provide valid results. The model can be suffered from heteroskedasticity where the variance of the error term is not constant. This problem can potentially lead to the inconsistency of the model and the t-test and confidence intervals can be misleading. While this is a serious problem, the model is still unbiased. This problem can be easily solved by using robust estimation. Another serious problem is endogeneity. The existence of endogeneity would cause the model to be biased, and the coefficients are misled. The potential reason for the existence of endogenity is omitted variables. Instrument variables (IV) are effective way to solve endogeneity. However, before making the model to be more complex, more controlling variables will be added to the model if the results of the original model reveals the existence of endogeneity.

\subsection{Research Limitation}

The major limitation of this research is the estimate of sentiment variables. The sentiment variables are constructed based on the secondary information obtained from the company performance and therefore they may not be as significant as expect. This is based on the consideration that the use of machine learning algorithms mining and coding techniques can be more efficient to construct the investor sentiments from qualitative information. In practice, this will require the mining of qualitative posts of investors in various social medias, and use proper coding technique to code the qualitative information, then use machine learning algorithms to perform multi classification estimates of the coefficients. This idea can be incorporated into future potential research. 


\section{CONCLUSION}

This research focuses on the study of loss aversion and overconfidence sentiment biases that could potentially impact on the performance of the listed companies in China. This research expects to provide the evidence to support that those sentiment variables are statistically significant to the listed companies in China. This expected result can be confirmed by the early study conducted by Be Bondt \& Thaler (1985). This research also expects that the pessimism of the investors that reflects loss aversion would show a negative influence on the performance of listed companies in China. Furthermore, this research also intends to find that the overconfidence sentiment would be beneficial to shareholders through higher stock returns. Many studies have been done on the relationship of biases and investment decision making but still there is a gap to bring in new moderators and mediators in it. Risk perception is an important mediator of the present study which is not tested before in such a basic mechanism. Biases are linked with the investment decision in most of the studies of developed countries, but there are less empirical studies conducted in developing countries like China. With the empirical model built in this research, more information about behavioral economics could be revealed.

\section{REFERENCES}

[1] F. Aftalion. Le point sur La behavioral finance. Banque et Marché, 2002, 2(56): 59-67.

[2] N. Barberis, M. Huang and T. Santos. Prospect theory and asset prices. Quarterly Journal of Economics, 2001, 116(1): 1-53.

[3] S. Benartzi, R.H. Thaler. Myopic loss aversion and the equity premium puzzle", Quarterly Journal of Economics, 1995, 110(1): 73-92.

[4] A.V. Benos. Aggressiveness and survival of overconfident traders. Journal of Financial Markets, 1998, 1(3/4): 353-383.

[5] F. Chau, R. Deesomsak, M.C.K. Lau. Investor sentiment and feedback trading: evidence from the exchange-traded fund markets. International Review of Financial Analysis, 2011, 20(5): 292305.

[6] W. Chuang, R. Susmel. Who is the more overconfident trader? Individual vs. institutional investors. Journal of Banking and Finance, 2011, 35(7): 1626-1644.

[7] K. Daniel, D. Hirshleifer and A. Subrahmanyam. Investor psychology and security market under- and overreactions. Journal of Finance, 1998, 53(6): $1839-1886$
[8] W.F.M. De Bondt and R. Thaler. Does the stock market overreact? Journal of Finance, 1985, 40(3): 793-805.

[9] D. Dreman, S. Johnson, D. MacGregor and P. Slovic. A report on the march 2001 investor sentiment survey. Journal of Psychology and Financial Markets, 2001, 2(3): 126-134.

[10] D. Hirshleifer and G.Y. Leo. On the survival of overconfident traders in a competitive securities market. Journal of Financial Markets, 2001, 4(1): 73-84.

[11] C.S. Jung, D.W. Lee and K.S. Park. Can investor heterogeneity be used to explain the cross- section of average stock returns in emerging markets. Journal of International Money and Finance, 2009, 28(4): 648-670.

[12] D. Kahneman and A. Tversky. Prospect theory: an analysis of decision under risk. Econometrica, 1979, 47(2): 263-291.

[13] A.S. Kyle, and F.A. Wang. Speculation duopoly with agreement to disagree: can overconfidence survive the market test. Journal of Finance, 1997, 52(5): 2073-2090.

[14] A. Rephael, S. Kandel, A. Wohl. Measuring investor sentiment with mutual fund flows. Journal of Financial Economics, 2012, 104(2): 363-382.

[15] J.H. Russo, P.J.H. Schoemaker. Managing overconfidence. Sloan Management Review, 1992, 33(2): 7-17.

[16] R.J. Shiller. Human behavior and the efficiency of financial system. Handbook of Macroeconomics, 1998, 1(20): 1305-1340.

[17] RH. Thaler, E.J. Johnson. Gambling with the house money and trying to break even: effects of prior outcomes on risky choice. Management Science, 1990, 6(6): 643-660. 